\title{
Atividade antimicrobiana in vitro do extrato de Abarema cochliocarpos (Gomes) Barneby \& Grimes
}

\author{
Sidnei C. Santos*, Fábio S. Ferreira, Juan C. Rossi-Alva, Luzimar G. Fernandez \\ Laboratório de Estudos em Meio Ambiente, Universidade Católica do Salvador, Av. Professor Pinto \\ de Aguiar, 2589, Pituaçu, 41740-090, Salvador, BA, Brasil
}

\begin{abstract}
RESUMO: O presente trabalho objetivou avaliar o potencial antimicrobiano in vitro do extrato hidro-alcoólico da casca de Abarema cochliocarpos (Gomes) Barneby \& Grimes, conhecido como barbatimão, nas cepas de Staphylococcus aureus (ATCC 6538), Micrococcus luteus (ATCC 9341), Escherichia coli (ATCC 10536), Pseudomonas aeruginosa (ATCC 15442) e Staphylococcus aureus isolado de amostra clínica (SAIACLIN). Coletaram-se cascas de um espécime de barbatimão no Parque Ecológico INDES, localizado em Vila de Sauípe, Bahia, para preparação do extrato hidroalcoólico. Os testes de susceptibilidade bacteriana foram realizados através do método de difusão em disco e da concentração inibitória mínima (CIM). O extrato hidro-alcoólico de A. cochliocarpos inibiu o crescimento somente das bactérias Gram-positivas. S. aureus (ATCC 6538), SAIACLIN e $M$. luteus apresentaram halos crescentes de inibição bacteriana de acordo com o aumento da concentração do extrato (1, 2 e $3 \mathrm{mg} /$ disco), que variaram entre 8 a $15 \mathrm{~mm}$, de 8 a $16 \mathrm{~mm}$ e de 13 a $22 \mathrm{~mm}$ para os respectivos microrganismos. Os resultados confirmaram a capacidade de inibição do crescimento bacteriano in vitro pelo extrato da casca de A. cochliocarpos, corroborando os relatos populares.
\end{abstract}

Unitermos: Abarema cochliocarpos, Mimosaceae, atividade antimicrobiana.

\begin{abstract}
In vitro antimicrobial activity of the extract of Abarema cochliocarpos (Gomes) Barneby \& Grimes”. The present study aimed at evaluating the in vitro antimicrobial potential of the hydroalcoholic extract from the bark of Abarema cochliocarpos (Gomes) Barneby \& Grimes, known as ‘barbatimão', over the strains of Staphylococcus aureus (ATCC 6538), Micrococcus luteus (ATCC 9341), Escherichia coli (ATCC 6538), Pseudomonas aeruginosa (ATCC 15442) and over a Clinical Sample isolated from Staphylococcus aureus (SAIACLIN). Samples of 'barbatimão' bark were collected from a specimen at the INDES Ecological Park, located at Vila de Sauípe, Bahia to prepare the hydroalcoholic extract. The bacterial susceptibility tests were carried through the disk diffusion method and through the minimum inhibitory concentration (MIC). The hydroalcoholic extract of A. cochliocarpos only inhibited the growth of the Gram-positive bacteria. S. aureus (ATCC 6538), SAIACLIN and M. luteus had presented increasing zones of bacterial inhibition in accordance with the increase of the extract concentration (1, 2 and $3 \mathrm{mg} / \mathrm{disco})$, that had varied between 8 to $15 \mathrm{~mm}$, from 8 to $16 \mathrm{~mm}$ and from 13 to $22 \mathrm{~mm}$ for the respective microorganisms. The results had confirmed the capacity of inhibition of the in vitro bacterial growth for the extract of the bark of $A$. cochliocarpos, corroborating the popular stories.
\end{abstract}

Keywords: Abarema cochliocarpos, Mimosaceae, antimicrobial activity.

\section{INTRODUÇÃO}

Embora muitas indústrias farmacêuticas tenham produzido novos antibióticos emodificado algumas drogas já existentes, nas últimas três décadas, a resistência a essas moléculas pelos microrganismos vem aumentando. Tal fato tem causado preocupação, pois cresce o número de pacientes em hospitais que tem a imunidade suprimida com o concomitante surgimento de linhagens de bactérias e fungos que apresentam novos perfis de resistência a antibióticos. Conseqüentemente, novas infecções poderão ocorrer em hospitais e/ou residências resultando em elevada morbidade e mortalidade (Farias et al., 1997;
Nascimento et al., 2000; Caetano et al., 2002; Oliveira et al., 2006a,b).

As plantas têm sido uma fonte valiosa de produtos para manutenção da saúde humana, sendo mais difundida especialmente nos últimos anos, após numerosos estudos com produtos terapêuticos de plantas medicinais. Segundo a Organização Mundial de Saúde (OMS), as plantas medicinais são a melhor fonte para se obter uma variedade de drogas, e cerca de $80 \%$ da população mundial usa a medicina tradicional na busca de alívio de alguma sintomatologia dolorosa ou desagradável (Nascimento et al., 2000; Caetano et al., 2002). A seleção de plantas a partir de informações 
da medicina tradicional ou popular pode conduzir a descoberta de moléculas promissoras (Hostettmann et al., 2003; Agra et al., 2007).

Abarema cochliocarpos, conhecida popularmente como barbatimão, é uma espécie endêmica do Brasil pertencente à família Mimosaceae. Trata-se de uma árvore frondosa de pequeno a médio porte, possuindo folhas compostas, inflorescência em glomérulos globosos, flores ligeiramente amareladas, frutos do tipo legume contorcido e sementes brancas acinzentadas (Santos, 2004), amplamente utilizada in natura no Brasil como planta medicinal (Migliatti, 2003). Sua casca é utilizada na forma de chá e tintura pela comunidade da Vila de Sauípe e de outras regiões da Bahia para o tratamento de feridas purulentas e inflamações da pele (Santos, 2004).

Este trabalho teve como objetivo avaliar o potencial antimicrobiano in vitro do extrato hidroalcoólico de Abarema cochliocarpos (Gomes) Barneby \& Grimes nas cepas de Staphylococcus aureus (ATCC 6835), Micrococcus luteus (ATCC 9341), Escherichia coli (ATCC 10536), Pseudomonas aeruginosa (ATCC 15442) e em uma linhagem de Staphylococcus aureus Isolado de Amostra Clínica (SAIACLIN) e determinar a concentração inibitória mínima (CIM).

\section{MATERIAL E MÉTODOS}

\section{Material}

Os meios de cultura utilizados foram o ágar TSA (Tryptic Soy Agar) (Merck) para o crescimento e manutenção das bactérias, o meio ágar Mueller-Hinton (Biobrás Diagnóstico) para os testes de avaliação de sensibilidade pelo método da difusão em disco e o caldo Mueller-Hinton (Himedia) para determinar a concentração inibitória mínima (CIM) do extrato vegetal. Os solventes utilizados nos experimentos foram o etanol para preparo do extrato vegetal e o dimetilsufóxido (DMSO) para ressuspensão do extrato e realização do teste de atividade antimicrobiana, ambos apresentando grau de pureza analítico Merck. Também foi usado o 2,3,5-Trifenil Tetrazólio Cloreto (TTC) (Nuclear) para revelar o ensaio da CIM. Os discos (Laboclin) e o pó (Henrifarma) de cloranfenicol foram usados como controle positivo nos ensaios. As suspensões bacterianas foram diluídas em solução salina estéril e padronizadas pela turbidez conforme a escala 0,5 de MacFarland: 0,5 $\mathrm{mL}$ de $\mathrm{BaCl}_{2} \cdot 2 \mathrm{H}_{2} \mathrm{O}(0,048 \mathrm{M})-1,75 \%(\mathrm{p} / \mathrm{v})$ em 99,5 mL de $\mathrm{H}_{2} \mathrm{SO}_{4}(0,36 \mathrm{~N})-1 \%(\mathrm{v} / \mathrm{v})$.

\section{Material vegetal}

A casca de Abarema cochliocarpos (Mimosaceae) foi coletada de acordo com a metodologia descrita por Campos (1991). A coletada foi realizada em agosto de 2004, no Parque Ecológico INDES (Instituto de Desenvolvimento Sustentável do Litoral Norte da Bahia), localizada em Vila de Sauípe, entre as coordenadas 12 $2^{\circ} 33^{\prime} 16^{\prime \prime}$ latitude Sul e 037 $55^{\prime} 27^{\prime \prime}$ longitude Oeste (Magellan - GPS 315), no município de Mata de São João, Bahia, Brasil.

A identificação da espécie foi realizada pela Dra. Hortência Pousada Bautista no Instituto Brasileiro de Geografia e Estatística (IBGE), e a exsicata encontrase depositada no acervo do Herbário Radambrasil (HRB) sob o número de registro 50992.

\section{Preparo do extrato}

A preparação do extrato hidro-alcoólico foi realizado através do método de maceração com etanol 70\% (v/v), utilizando-se a proporção de 200 mL/68g entre solvente/soluto. A casca de A. cochliocarpos foi seca em estufa a $35^{\circ} \mathrm{C}$, triturada e macerada; duas vezes, por dois dias, a temperatura ambiente e mantida ao abrigo da luz (Matos, 1988). Ao final deste processo, os extratos foram filtrados em papel filtro qualitativo $15 \mathrm{~cm}$ (Qualy $14 \mu \mathrm{m}$ ) com o auxílio da Bomba de Vácuo (Marconi - MA 057/1). O solvente foi evaporado através da utilização do evaporador rotatório (Heidolph - Laborata 4000) a $40{ }^{\circ} \mathrm{C}$ e do "Air-dryer" (Daihatsu - Taiff 2100) para eliminação total do solvente, de acordo com a metodologia utilizada. O extrato foi armazenado em frasco âmbar e conservado no dessecador até o preparo das soluções em diferentes concentrações (Williamson et al., 1996).

\section{Microrganismos}

Quatro cepas bacterianas foram usadas no controle de sensibilidade dos ensaios: Staphylococcus aureus ATTC 6835, Micrococcus luteus ATCC 9341, Escherichia coli ATCC 10536, Pseudomonas aeruginosa ATCC 15442 e uma linhagem de Staphylococcus aureus Isolado de Amostra Clínica (SAIACLIN), que apresenta resistência à penicilina, ampicilina e sensibilidade intermediária a tetraciclina, doada por um laboratório privado de Salvador-BA.

\section{Avaliação da atividade antimicrobiana}

Os ensaios antimicrobianos foram realizados em triplicata através do método de difusão em disco de papel filtro (Whatman - tipo 3) de 6,0 mm de diâmetro em meio ágar Mueller-Hinton. Os inóculos foram obtidos a partir de culturas recentes dos microrganismos (entre $18-24$ h a $37^{\circ} \mathrm{C}$ ), preparando-se suspensões padronizadas através da escala 0,5 de MacFarland (Oplustil et al., 2000; Koneman, 2001). O extrato hidro-alcoólico da casca de A. cochliocarpos foi testado pelo método de triagem em três concentrações (1, 2 e 3 mg/disco). Os discos foram impregnados com alíquotas do extrato nas concentrações descritas na tabela 1, e no teste controle foi adicionado $10 \mu \mathrm{L}$ de DMSO, que foi utilizado para ressuspensão do extrato. Como controle positivo utilizou-se o disco 
de cloranfenicol $(30 \mu \mathrm{g})$. As culturas com os discos foram incubadas a $37^{\circ} \mathrm{C}$ por $18 \mathrm{~h}$. Os resultados foram obtidos através da mensuração do diâmetro dos halos de inibição formados ao redor dos discos (NCCLS, 2003a), com auxílio de um halômetro e expressos em milímetros
(Carvalho-Júnior et al., 2004; Lima et al., 2000).

\section{Determinação da Concentração Inibitória Mínima (CIM)}

Tabela 1. Preparo das soluções do extrato da casca de Abarema cochliocarpos com as respectivas alíquotas ( $\mu \mathrm{L})$ e massas (mg) por disco.

\begin{tabular}{c|c|c}
\hline Solução de Trabalho & Alíquota & Massa de Extrato por Disco \\
\hline 100 & 10 & 1 \\
100 & 20 & 2 \\
100 & 30 & 3 \\
\hline
\end{tabular}

Os ensaios de sensibilidade de microdiluição em caldo foram feitos em triplicata, seguindo as recomendações da NCCLS (2003b). Os testes foram realizados em caldo Mueller-Hinton contido em microplacas de 96 poços. O extrato hidro-alcoólico da casca de A. cochliocarpos foi depositado nos poços, seguindo a técnica de diluição em série, na escala de 0,0098 a 20,0000 mg/mL. Foi realizado controle do extrato, do caldo Mueller-Hinton, dos microrganismos e do cloranfenicol. As placas foram incubadas a $37^{\circ} \mathrm{C}$ por $24 \mathrm{~h}$. A leitura foi realizada através da mudança de cor da solução reveladora (TTC), considerando o resultado positivo a ausência de coloração e negativo na presença de coloração rosa-avermelhada.

\section{Análise estatística}

Os resultados foram avaliados através da análise estatística descritiva e de testes não-paramétricos de Kruskal-Wallis e de Mann-Whitney U (Beiguelman, 2002; Callegari-Jacques, 2003). Foi utilizado o programa estatístico GraphPad InsTat (versão 3) para análise dos dados. Os testes foram considerados significantes quando o valor de $P$ foi menor que 0,05 .

\section{RESULTADOS E DISCUSSÃO}

Os ensaios de atividade antimicrobiana in vitro mostraram que o extrato hidro-alcoólico da casca de Abarema cochliocarpos inibiu o crescimento das cepas Gram-positivas, mas não foi capaz de inibir o crescimento das cepas Gram-negativas.

As culturas de S. aureus (ATCC 6835), SAIACLIN e M. luteus (ATCC 9341) apresentaram halos crescentes de inibição de crescimento bacteriano, de acordo as concentrações testadas (1, 2 e $3 \mathrm{mg} /$ disco), variando entre 8 e $9 \mathrm{~mm}, 11$ a $13 \mathrm{~mm}$ e 14 e $15 \mathrm{~mm}$ para S. aureus (ATCC 6835); de 8 a $10 \mathrm{~mm}, 12$ e $13 \mathrm{~mm}$ e 14 e $16 \mathrm{~mm}$ para SAIACLIN; e 13 e $14 \mathrm{~mm}, 17$ e $18 \mathrm{~mm}$ e 21 e 22 mm para M. luteus; nas concentrações de 1, 2 e 3 $\mathrm{mg} /$ disco, respectivamente (Tabela 2).

A capacidade de inibição do crescimento bacteriano do extrato da casca de A. cochliocarpos frente às cepas Gram-positivas pode estar diretamente relacionado com a estrutura da parede celular das mesmas. Tendo em vista que essa é a principal característica que

Tabela 2. Halos de inibição (mm) obtidos pelo método de difusão em disco utilizado na análise do extrato hidro-alcoólico da casca de $A$. cochliocarpos em diferentes concentrações.

\begin{tabular}{|c|c|c|c|c|c|c|c|c|c|c|c|c|c|c|c|}
\hline \multirow{3}{*}{$\begin{array}{c}\text { Concentração } \\
\text { (mg/disco) }\end{array}$} & \multicolumn{15}{|c|}{ Diâmetro do Halo de Inibição (mm) } \\
\hline & \multicolumn{5}{|c|}{35} & \multicolumn{5}{|c|}{ SAIACLIN } & \multicolumn{5}{|c|}{ M. luteus ATCC 9341} \\
\hline & $\mathrm{T} 1$ & $\mathrm{~T} 2$ & $\mathrm{~T} 3$ & MA & DP & $\mathrm{T} 1$ & $\mathrm{~T} 2$ & T3 & MA & DP & $\mathrm{T} 1$ & $\mathrm{~T} 2$ & T3 & MA & DP \\
\hline 1 & 8,00 & 9,00 & 9,00 & & 0,58 & 8,00 & 10,00 & 9,00 & & 1,00 & 14,00 & 14,00 & 13,00 & 13,67 & 0,5 \\
\hline 2 & & & & & 1,00 & 13,00 & 13,00 & 12,00 & 12 , & 58 & & & 8,00 & 17 , & 0,5 \\
\hline 3 & 14,00 & 14,00 & 15,00 & 14,33 & 0,58 & 16,00 & 14,00 & 16,00 & 15,33 & 1,15 & 20,00 & 21,00 & 22,00 & 21,00 & 1,0 \\
\hline & & & & & & & & & & & & & & & \\
\hline
\end{tabular}

MA: Média Aritmética; DP: Desvio Padrão.

separa os dois grupos e também devido à presença da membrana externa das cepas Gram-negativas, pois ela age como barreira para certos tipos de antibióticos, enzimas digestivas, detergentes e metais pesados (Tortora; Funke;
Case, 2003).

Mesmo o SAIACLIN possuindo um perfil de sensibilidade de resistência para alguns antibióticos, quando comparado com a cepa de S. aureus (ATCC 
6835) não houve diferença significativa $(P<0,05)$ de inibição do crescimento pelo extrato da casca de $A$. cochliocarpos, ao utilizar o teste de Mann-Whitney U, sendo o valor de $P$ : $0,70,0,40$ e 0,40 , nas concentrações de 1, 2 e $3 \mathrm{mg} /$ disco, respectivamente. Entretanto, quando comparado às médias dos diâmetros dos halos de inibição do crescimento de $S$. aureus (ATCC 6835), SAIACLIN e $M$. luteus (ATCC 9341) pelo teste de Kruskal-Wallis, os resultados foram considerados significativo, sendo o $P$ igual a 0,04 para as concentrações de 1,2 e $3 \mathrm{mg} /$ disco, respectivamente. Essa diferença é decorrente da maior sensibilidade da cepa de $M$. luteus ao extrato da casca de A. cochliocarpos, que possibilitou a formação de halos de inibição do crescimento superior ao SAIACLIN e a cepa de $S$. aureus.

O extrato hidro-alcoólico da casca de Abarema cochliocarpos apresentou um CIM de 0,1562 mg/mL para $M$. luteus e de $0,3125 \mathrm{mg} / \mathrm{mL}$ para S. aureus (ATCC $6835)$ e SAIACLIN. O resultado do teste de KruskalWallis confirma a diferença significativa $(P=0,0498)$ das concentrações inibitórias mínimas do extrato de $A$. cochliocarpos frente aos microrganismos testados.

A descoberta de plantas endêmicas com reconhecido potencial terapêutico tem sido aplicada pelas comunidades tradicionais com resultados satisfatórios, mas novos estudos necessitam ser conduzidos em busca do isolamento, da purificação e da identificação de novos compostos químicos (Hostettmann et al., 2003). A sociedade necessita de novos fármacos de qualidade e economicamente viáveis para combater as inúmeras ocorrências médicas e que possam ser usufruídos por todos.

\section{CONCLUSÃO}

As recomendações da medicina popular auxiliam consideravelmente na busca e seleção dos modelos farmacológicos a serem utilizados, como a utilização da Abarema cochliocarpos pela comunidade da Vila de Sauípe, resultando na descoberta de promissoras substâncias fito e quimioterápicas no combate aos microrganismos. Os testes desenvolvidos para avaliar a atividade antimicrobiana in vitro com o extrato hidroalcoólico de A. cochliocarpos sinalizam uma capacidade de inibição do crescimento de bactérias Gram-positivas, principalmente da família Micrococcaceae. Entretanto, novos testes in vitro com extratos de outras polaridades ainda precisam ser realizados, bem como a purificação e identificação do componente bioativo. Dessa forma, a busca pela atividade antimicrobiana de extratos vegetais poderá colaborar na descoberta de novas alternativas mais eficazes e econômicas para combater infecções causadas por microrganismos.

\section{AGRADECIMENTOS}

Os autores agradecem ao Prof. José Carlos
Santos da Silva por fornecer o SAIACLIN; ao Laboratório de Pós-graduação em Química - Iq/UFBa, na pessoa de Jorge Maurício David pela colaboração no preparo do extrato; a prof ${ }^{a}$ Lectícia Scardino Scott Faria e ao Dr. Geraldo Carlos Pereira Pinto pela colaboração na classificação sistemática do vegetal. Também expressamos a nossa gratidão ao Laboratório de Estudos em Meio Ambiente - LEMA/UCSal pela infra-estrutura para a realização deste trabalho.

\section{REFERÊNCIAS}

Agra MF, França PF, Barbosa-Filho JM 2007. Synopsis of the plants known as medicinal and poisonous in Northeast of Brazil. Rev Bras Farmacogn 17: 114-140.

Beiguelman B 2002. Curso prático de bioestatística. São Paulo: FUNPEC.

Caetano N, Saraiva A, Pereira R, Carvalho D, Pimentel MCB, Maia MBS 2002. Determinação de atividades antimicrobiana de extratos de plantas de uso popular como antiflamatório. Rev Bras Farmacogn 12(Supl.): 132-135.

Callegari-Jacques, SM 2003. Bioestatística: princípios e aplicações. Porto Alegre: ARTMED.

Campos JM 1991. Guia prático de terapêutica externa: métodos e procedimentos terapêuticos de grande simplicidade e eficácia. São Paulo: Cultrix/Pensamento.

Carvalho-Júnior PM, Rodrigues RFO, Sawaya ACHF, Marques MOM, Shimizu MT 2004. Chemical composition and antimicrobial activity of the essential oil of Cordia verbenacea D.C. J Ethnopharmacol 95: 297-301.

Farias WVL, Sader HS, Leme IL, Pignatari AC 1997. Padrão de sensibilidade de 117 amostras clínicas de Staphylococcus aureus isolados em 12 hospitais. Rev Ass Med 43: 199-204.

Hostettmann K, Queiroz EF, Vieira PC 2003. Princípios ativos de plantas superiores. São Paulo: EDUFSCAR.

Koneman EW 2001. Diagnóstico microbiológico. 5.ed. Rio de Janeiro: MEDSI, p.551-578.

Lima CAA, Pastore GM, Lima EDPA 2000. Estudo da atividade antimicrobiana dos ácidos anacárdicos do óleo da casca da castanha de caju (CNSL) dos clones de cajueiroanão-precoce CCP-76 e CCP-09 em cinco estágios de maturação sobre microrganismos da cavidade bucal. Ciência e Tecnologia de Alimentos 20: 358-362..

Matos FJA 1988. Introdução a fitoquímica experimental. Fortaleza: EUFC.

Migliatti JFZ 2003. Barbatimão: Stryphnodendron spp., Leguminosae. Jornal Brasileiro de Fitomedicina 3235.

Nascimento GGF, Locatelli J, Freitas PC Silva GL 2000. Antibacterial activity of plant extracts and phytochemicals on antibiotic-resistant bacteria. Braz J Microbiol 31: 247-256.

NCCLS (Clinical and Laboratory Standards Institute) 2003a. Performance standards for antimicrobial disk susceptibility tests: approved standard. NCCLS 
document M2-A8 (ISBN 1-56238-485-6), Wayne, Pennsylvania.

NCCLS (Clinical and Laboratory Standards Institute) 2003b. Methods for dilution antimicrobial susceptibility tests for bacteria that grow aerobically: approved standard. NCCLS document M7-A6 (ISBN 1-56238-486-4), Wayne, Pennsylvania.

Oliveira RAG, Lima EO, Vieira WL, Freire KRL, Trajano VN, Lima, IO, Souza EL, Toledo MS, Silva-Filho RN 2006. Estudo da interferência de óleos essenciais sobre a atividade de alguns antibióticos usados na clínica. Rev Bras Farmacogn 16: 77-82.

Oliveira FP, Lima EO, Siqueira Júnior JP, Souza EL, Santos BHC, Barreto HM 2006. Effectiveness of Lippia sidoides Cham. (Verbenaceae) essential oil in inhibiting the growth of Staphylococcus aureus strains isolated from clinical material. Rev Bras Farmacogn 16: 510-516.

Oplustil CP, Zoccoli CM, Tobuti NR, Sinto SI 2000. Procedimentos básicos em microbiologia clínica. São Paulo: Sarvier.

Santos SC 2004. Atividade antimicrobiana in vitro de extrato de Abarema cochliocarpos (Gomes) Barneby \& Grimes em Staphylococcus aureus. Salvador, 39p. Trabalho apresentado como requisito parcial para a aprovação na Disciplina Ciências do Ambiente, Instituto de Ciências Biológicas, Universidade Católica do Salvador.

Tortora GJ, Funke BR, Case CL 2003. Microbiologia. Porto Alegre: ArtMed.

Williamson EM, Okpako DT, Evans FJ 1996. Pharmacological methods in phytotherapy reseaach: selection, preparation and pharmacological evaluation of plant material. New York: John \& Sons. 